\title{
Risk Factor of Elevated Blood Pressure Among Children in Tulikup Village, Bali
}

\author{
Christin Natalia Kalembang*, Gusti Ayu Putu Nilawati, Bagus Ngurah Mahakrishna
}

Department of Child Health, Medical Faculty of Udayana University, Sanglah General Hospital, Denpasar, Indonesia

Email address:

christinkalembang@gmail.com (C. N. Kalembang),drnilaspa@gmail.com (G. A. P. Nilawati),

bagusngurahmahakrishna@gmail.com (B. N. Mahakrishna)

${ }^{*}$ Corresponding author

\section{To cite this article:}

Christin Natalia Kalembang, Gusti Ayu Putu Nilawati, Bagus Ngurah Mahakrishna. Risk Factor of Elevated Blood Pressure Among Children in Tulikup Village, Bali. American Journal of Pediatrics. Vol. 7, No. 3, 2021, pp. 100-104. doi: 10.11648/j.ajp.20210703.12

Received: May 31, 2021; Accepted: June 15, 2021; Published: June 23, 2021

\begin{abstract}
Elevated blood pressure in children is a worldwide problem, constitute as major, often overlooked, public health problem in many countries. Normal blood pressure value in children varies based on age, sex and body height which available in standardized table. Measurement of blood pressure is crucial and needed to be done at least once a year in every child with risk factors. Risk factors for elevated blood pressure includes family history of hypertension, salt intake, physical activity, stress level and obesity. Therefore we aimed to determine risk factors for elevated blood pressure among children in Tulikup village Bali. This observational analytic study with cross-sectional design, was conducted in children age 1-18 years old whom visit child health community service program in Tulikup. We collected data from 81 children, age range from 1 to 13 years old, with median age was 4 years old. Data was collected by using questionnaire and physical examination. This study was dominated by female and elevated blood pressure (11.1\%). On the other hand, nutritional status were both equal between wellnourished status and mild nutrition (44.4\%). Multivariate analysis showed two factors associated with elevated blood pressure such as family history of hypertension with $\mathrm{p}=0.045$ (OR 8.89; $95 \%$ CI $1.05-75.29$ ) and excessive salt intake with $\mathrm{p}=0.046$ (OR 5.24; 95\% CI 1.02-26.77). Therefore risk factors such as family history of hypertension and excessive salt intake, significantly cause elevated blood pressure in children.
\end{abstract}

Keywords: Children, Blood Pressure, Elevated Blood Pressure, Hypertension

\section{Introduction}

Elevated blood pressure in children is a worldwide problem and constitute as major, often overlooked, public health problem in many countries. Annual blood pressure screening needs to be performed on every visit especially for those with risk factors [1].

Elevated blood pressure is defined as blood pressure of systolic and/or diastolic blood pressure $\geq 90^{\text {th }}$ percentile to $<95^{\text {th }}$ percentile or $120 / 80 \mathrm{mmHg}$ to $<95^{\text {th }}$ percentile +12 $\mathrm{mmHg}$ (for children aged 1-13 years of age) and 120/<80 $\mathrm{mmHg}$ (for children aged $\geq 13$ years old) based on age, gender and body height. Children with elevated blood pressure may progress to hypertension during childhood, adolescence, or adulthood, which is confirmed through blood pressure monitoring. Ambulatory blood pressure monitoring should be performed to confirm elevated blood pressure [2]. About 2.5-
$3.7 \%$ cases of elevated blood pressure develop into hypertension [2].

Hypertension is the most common form of blood pressure problem in clinical practice which frequently found in adolescents and adults rather than in young children. The pathogenesis of essential hypertension is affected by many factors such as obesity, insulin resistance, inappropriate activation of sympathetic nervous system, alterations in sodium hemostasis, renin angiotensin system, vascular smooth muscle structure and function, genetic factors and fetal programming. All those have implication in circulatory disorder $[1,2]$.

Hypertension in children has lower prevalence compared to adult. Children tend to have normotension and elevated blood pressure in the population [3,4]. Some evidence suggests that essential hypertension in adults is a continuation of that in children [5]. AAP stated the 
prevalence of hypertension in children was $3.5 \%$ in 2017 , meanwhile the prevalence of elevated blood pressure was between $2.2 \%$ and $3.5 \%$ [6]. Moreover the survey from Indonesian Ministry of Health found that $8.4 \%$ children suffered hypertension in 2017 [7]. Another study from Wati et al. stated that the prevalence of children with elevated blood pressure was 233 children (18.5\%), hypertension grade 1 was 279 children $(22.2 \%)$ and hypertension grade 2 was 177 children (14.1\%) [8].

History taking and physical examination are crucial to determine primary or secondary hypertension in child with elevated blood pressure [2]. Primary hypertension occurs when the cause of hypertension is unknown or unexplainable, usually related to family history of hypertension (heritability is about 50\%), salt intake, physical activity, stress level and obesity $[5,9]$. Secondary hypertension occurs when one suffers from other underlying diseases and is the most frequent type of hypertension in children [10-12]. Furthermore the elevated blood pressure in children can also cause complications, such as stroke, heart attack, heart failure and kidney disease [3, 4].

Therapeutic lifestyle changes such as weight loss if overweight or obese, healthy diet and regular exercise are crucial in children with elevated blood pressure. All those can lower blood pressure, reduce the development cardiovascular disease so does not become hypertension in the future [2].

Hypertension in children is multifactorial and cannot be ascertained as single cause. Blood pressure testing in children is usually not routinely perform in health center. Tulikup Village is located at southeast border of Gianyar regency. In addition social service program is carried out with the aim of planning appropriate programs and interventions for the people of Tulikup Village, especially for general health. We aimed to determine the blood pressure among children in Tulikup Village which is related to child health community service program.

\section{Method}

We conduct an observational analytic study with crosssectional design using questionnaire and physical examination including measurement of body height, body weight and blood pressure in Tulikup Village on December $15^{\text {th }}, 2019$. The subject of this study were all children who visited public health center for the child health community service program. We used total sampling technique and data variable include gender, age, nutritional status, family history of hypertension, salt intake and physical activity were recorded.
Data were analyzed using computer program, bivariate analysis used prevalence ratio by chi square and multivariate analysis used odds ratio by logistic regression with $95 \%$ confident interval (CI) and statistically significant if p-value $<0.05$. The study has been approved by Ethics Committee of Medical Faculty of Medicine / Sanglah Hospital with ethical clearance 2483/UN 14.2.2. VII. 14/LT/2020.

\section{Result}

Total sample in this study was 81 children whom participated in the child health community service program on December $15^{\text {th }}, 2019$. Characteristic of samples was shown in Table 1 their median age was 4 years old (1-13 years), most of them were female 44 (54.3\%). Nutritional status was equally both of well-nourished 36 (44.4\%) and mild malnutrition $36(44.4 \%)$. Children with family history of hypertension and suffered elevated blood pressure 9 (11.1\%).

Table 1. Characteristic of subjects.

\begin{tabular}{ll}
\hline Characteristic of subjects & $\mathbf{n}=\mathbf{8 1}$ \\
\hline Age, median (range), years old & $4(1-13)$ \\
Gender, n (\%) & $37(45.7)$ \\
Male & $44(54.3)$ \\
Female & \\
Nutritional Status, $\mathrm{n}(\%)$ & $2(2.5)$ \\
Obesity & $7(8.6)$ \\
Overweight & $36(44.4)$ \\
Well nourished & $36(44.4)$ \\
Mild malnutrition & \\
Family history of hypertension, $\mathrm{n}(\%)$ & $9(11.1)$ \\
Yes & $72(88.9)$ \\
No & \\
Excessive salt intake, $\mathrm{n}(\%)$ & $29(35.8)$ \\
Yes & $52(64.2)$ \\
No & \\
Physical activity (hour/days), n (\%) & $13(16)$ \\
Inadequate & $68(84)$ \\
Adequate & \\
Elevated blood pressure, $\mathrm{n}(\%)$ & $72(88.9)$ \\
Non elevated & $9(11.1)$ \\
Elevated & 0 \\
Hypertension grade I & 0 \\
Hypertension grade II & \\
\hline
\end{tabular}

Bivariate analysis, showed family history of hypertension and excessive salt intake were associated with elevated blood pressure. Furthermore, those risk factors were independently associated with elevated blood pressure by multivariate analysis, as shown in Table 2 and Table 3.

Table 2. Blood pressure classification based on the characteristic of the subjects.

\begin{tabular}{|c|c|c|c|c|c|}
\hline \multirow{2}{*}{ Variables } & \multicolumn{2}{|c|}{ Blood Pressure } & \multirow{2}{*}{ PR } & \multirow{2}{*}{$95 \%$ CI } & \multirow{2}{*}{ p-valuc } \\
\hline & Elevated $\mathrm{n}=9$ & Normal $n=72$ & & & \\
\hline Gender, n (\%) & & & & & \\
\hline Male & $3(8.1)$ & $34(91.9)$ & 0.6 & $(0.16-2.21)$ & 0.498 \\
\hline $\begin{array}{l}\text { Female } \\
\text { Nutritional Status, n (\%) }\end{array}$ & $6(13.6)$ & $38(86.4)$ & & & \\
\hline Overweight-obesity & $2(22.2)$ & $7(77.8)$ & 2.3 & $(0.56-9.37)$ & 0.261 \\
\hline
\end{tabular}




\begin{tabular}{|c|c|c|c|c|c|}
\hline \multirow{2}{*}{ Variables } & \multicolumn{2}{|c|}{ Blood Pressure } & \multirow{2}{*}{ PR } & \multirow{2}{*}{$95 \% \mathrm{CI}$} & \multirow{2}{*}{ p-value } \\
\hline & Elevated $n=9$ & Normal $n=72$ & & & \\
\hline Mild malnutrition-well nourished & $7(9.7)$ & $65(90.3)$ & & & \\
\hline \multicolumn{6}{|l|}{ Family history of hypertension, n (\%) } \\
\hline Yes & $3(33.3)$ & $6(66.7)$ & 4 & $(1.20-13.28)$ & 0.024 \\
\hline No & $6(8.3)$ & $66(91.7)$ & & & \\
\hline \multicolumn{6}{|l|}{ Excessive salt intake, $\mathrm{n}(\%)$} \\
\hline Yes & $6(20.7)$ & $23(79.3)$ & 3.58 & $(0.96-13.28)$ & 0.041 \\
\hline \multicolumn{6}{|l|}{ Physical Activity, n (\%) } \\
\hline Inadequate & $2(15.4)$ & $11(84.6)$ & 1.49 & $(0.35-6.40)$ & 0.593 \\
\hline Adequate & $7(10.3)$ & $61(89.7)$ & & & \\
\hline
\end{tabular}

Table 3. Multivariate analysis based on risk factors for hypertension.

\begin{tabular}{llll}
\hline Variables & OR & 95\% CI & p-value \\
\hline Female & 0.49 & $0.08-3.01$ & 0.442 \\
Overweight-obesity & 2.61 & $0.28-24.36$ & 0.400 \\
Family history of hypertension & 8.89 & $1.05-75.29$ & 0.045 \\
Excessive salt intake & 5.24 & $1.02-26.77$ & 0.046 \\
Inadequate Physical Activity & 0.26 & $0.02-3.01$ & 0.282 \\
\hline
\end{tabular}

\section{Discussion}

Elevated blood pressure in children may progress to hypertension during childhood, adolescence, or adulthood. A study by Fuiano et al. in France found that elevated blood pressure more frequent in female $(35.1 \%)$ rather than males (41\%) [13]. In addition Genovesi et al. also found that the prevalence of elevated blood pressure was significantly higher in females $(5.4 \%)$ than males $(3.1 \%)$.

Song et al. found that the prevalence of elevated blood pressure among children at 6 to 19 years of age varied from $75 \%$ to $79 \%$ before the onset of puberty and during puberty, reach to peak level at the end of puberty and steadily decrease until the beginning of adulthood [15]. Liang et al. found elevated blood pressure was significant higher in children of the age group 6 compared with those in the middle age group [16]. A study by Noubiap et al. found prevalence elevated blood pressure 2 to 5 years of age was $10.7 \%$ [4]. In this study found that elevated blood pressure prevalence in 4 years of age $(5 \%)$.

Risk factors related to elevated blood pressure include family history of hypertension, salt intake, physical activity, stress level and obesity $[5,9]$. Children obesity has become a major global health concern in recent decades with increasing prevalence in developing countries [17]. Children obesity is associated with many cardiovascular risk factors such as elevated blood pressure, dyslipidemia, abnormalities of endothelial function and hyperinsulinemia [18]. Although primary hypertension is closely associated with obesity, some patients who are obese are not considered to be hypertensive. A study by Dulskine et al. showed significant association between overweight and obesity and high blood pressure with (overweight: $\mathrm{OR}=2.62$; 95\% CI 3.02-4.19; obesity: $\mathrm{OR}=6.64 ; 95 \%$ CI 4.65-9.49) [18]. Another study by Parker et al. found that obese child age 3 to 11 had significantly higher risk of developing hypertension $(\mathrm{HR}=2.02 ; 95 \% \mathrm{CI}$ 1.28-7.04) and the risk in obese adolescent was similar high
( $\mathrm{HR}=2.02 ; 95 \%$ CI 1.24-3.91) compared with lean child [19]. In this study found no significant difference was found between overweight and obesity as risk factor to hypertension from univariate analysis $(\mathrm{OR}=2.61 ; 95 \% \mathrm{CI}$ $0.280-24.36$, and $p=0.40$ ).

Family history is a consistent and independent risk factor for many common chronic diseases. The presence of genetic factor in the family can cause the risk of hypertension $80 \%$ indicating huge contribution of genetic for phenotype manifestation at this early age. A study conducted by Bilal et al. found that children with family history of hypertension 1.43 times more likely to develop hypertension ( $p=0.04$, $\mathrm{OR}=1.43 ; 95 \% \mathrm{CI} 1.88-3.31)$ and 1.32 times more likely to have elevated blood pressure $(p=0.02, \mathrm{OR}=1.32 ; 95 \% \mathrm{CI}$ 1.32-4.43) compared to children with normal BMI aged between 8 and 12 years [20]. Gomes et al. found that family history of hypertension was also independently associated with primary hypertension in childhood. The presence of family history of hypertension can increase a three-fold in the risk of primary hypertension $(\mathrm{OR}=3.03$; 95\% CI 1.04-8.79) [21]. In this study, family history of hypertension plays significant role in determining the risk of hypertension in children ( $p=0.04, \mathrm{OR}=8.89 ; 95 \%$ CI 1.05-75.29).

Sodium as the most abundant extracellular cation, plays important role in determining fluid balance. In early life, a positive sodium balance is needed for growth since newborns and preterm infants tend to lose sodium via their kidneys. Meanwhile among older children and adults, excessive salt intake leads to volume expansion and arterial hypertension $[14,22]$. Similar with study by Genovesi et al. reported salt intake $>2.5$ gram/day increased the prevalence of hypertension to $15-20 \%$ [14]. Leyvraz et al. showed that children with the higher intake of sodium had higher risk of having elevated blood pressure than children with lower sodium intakes (OR 2.00, 95\% CI 1.38-2.62) [23]. He et al. found significant association between salt intake and systolic blood pressure. Increment 1 gram/day of salt intake related to increment of systolic blood pressure $0.4 \mathrm{mmHg}$ and 0.6 
$\mathrm{mmHg}$ in pulse pressure with $\mathrm{p}<0.001$ [24]. In this study we found excessive salt intake statistically significant associated with hypertension ( $p=0.04, \mathrm{OR}=5.24 ; 95 \%$ CI 1.02-26.77).

The underlying mechanisms of physical activity in reducing blood pressure and prevent the development of hypertension remain unclear. This is due to the fact that the etiology of hypertension is multifactorial in nature and the interaction of these factors in contributing to the development of hypertension unclear. Meanwhile animal studies suggest aerobic exercise may prevent hypertension through alterations of insulin sensitivity and autonomic nervous system function, while resistance training may prevent increases of blood pressure through alterations in vasoconstriction regulation [24]. Kelley et al. found physical activity decrease blood pressure but not statistically significant with length of the study ranged from 36 weeks and training duration from 10-75 minutes. However, both regular physical activity and decrease of sedentary activity (such as watching television and playing video games) are important components of childhood obesity treatment and prevention [25]. Bilal et al. found limited physical activity does not significantly contribute to developing hypertension with $(p=0.38, \mathrm{OR}=0.54 ; 95 \% \mathrm{CI}$ $0.32-1.67)$ [20]. This study found that physical activity was not a significant risk factor for hypertension $(p=0.28$, $\mathrm{OR}=0.26$; 95\% CI 0.02-3.01).

Limitations of the study consist of: (1) The duration of this study was relatively short to provide education for parents and participants about elevated blood pressure and hypertension; (2) Further prospective study is needed to determine the risk factor for elevated blood pressure in children; (3) This study did not analyze the type of diet like food recall in obese/overweight and did not analyze type of physical activity.

\section{Conclusion}

This study showed elevated blood pressure is particularly high in children at the age of four and we found an association between family history of hypertension and excessive salt intake as risk factor for essential hypertension in children. Therefore, preventing elevated blood pressure can be performed by maintaining healthy diet and lifestyle.

\section{References}

[1] Zhang T, Harville E, Bazzano, He Jiang, Chen w. (2017). Can pediatric hypertension criteria be simplified? A Prediction Analysis of Subclinical Cardiovascular Outcomes from fhe Bogalusa Heart Study. Hypertension. 69 (4): 691-6.

[2] Riley M, Bluhm B. (2012). High blood pressure in children and adolescents. Am Fam Physician. 85 (7): 693-700.

[3] Chirag B, Chavda J, Kakkad KM, Damor P. (2013). A study of prevalence of hypertension in school children. Gujarat Medical Journal. 68 (2): 79-81.

[4] Noubiap JJ, Essouma M, Bigna JJ, Jingi AM, Aminde LN,
Nansseu JR. (2017). Prevalence of elevated blood pressure in children and adolescents in Africa: a systematic review and meta-analysis. Lancet Public Health. 2 (8): 375-86.

[5] Haris S, Dimiati H, Anwar MS. (2013). Profil hipertensi pada anak di RSUD Dr. Zainoel Abidin Banda Aceh. Sari Pediatri. 15 (2): 105-10.

[6] Flynn, Joseph T, Kaelber DC, Carissa MB, Blowey D, Aaron $\mathrm{E}$, et al. (2017). Clinical practice guidelines for screening and management of high blood pressure in children and adolescents. American Academy of Pediatrics. 140: 74.

[7] Dewi R, Ramayanti R, Rosdiana N, Ramayani OR, Siregar R, Siregar B. (2019). Waist circumference, body mass index, and skinfold thickness as potential risk factors for high blood pressure in adolescent. Pediatr indones. 59 (2): 79-86.

[8] Wati DK, Yuliatni CD, Dinata MK, Nilawati GAP, Widiana GR, Sutawan IBR, et al. (2019). Child blood pressure profile in Bali, Indonesia. Maced J Med Sci. 7 (12): 1962-67.

[9] Saing JH. (2005). Hipertensi pada remaja. Sari Pediatri. 6 (4): 159-65.

[10] Pungky AK, Damanik MP. (2006). Hipertensi pada anak di RS Dr. Sardjito Yogyakarta. Berita Kedokteran Masyarakat. 22 (3): 124-7.

[11] Siverstein DM, Champoux E, Aviles DH, Vehaskari VM. (2006). Treatment of primary and secondary hypertension in children. Pediatr Nephrol. 21: 820-7.

[12] Ban O, Ead A. (2013). Childhood hypertension and family history of hypertension in primary school children in Port Harcourt. Niger J Paed. 40 (2): 184-8.

[13] Fuiano N, Luciano A, Pilotto L, Pietrobelli A. (2006). Overweight and hypertension: longitudinal study in schoolaged children. Minerva Pediatr. 58: 451-9.

[14] Genovesi S, Giussani M, Pieruzzi F, Vigorita F, Arcovio C, et al. (2005). Results of blood pressure screening in a population of school-aged children in the province of Milan: role of overweight. J Hypertens. 23: 493-7.

[15] Song P, Zhang Y, yu J, Zha M, et al. (2019). Global prevalence of hypertension in children a systematic review and meta-analysis. Pediatr. 173 (12): 1154-63.

[16] Liang X, Xiao L, Luo Y, Xu J. (2020). Prevalence and risk factors of childhood hypertension in urban-rural areas of China: a cross-sectional study. Int J Hypertens. 12: 1-18.

[17] Basiratnia M, Derakhshan D, Ajdari S, Saki F. (2013). Prevalence of childhood obesity and hypertension in south of Iran. Iran J Kidney Dis. 7: 282-8.

[18] Dulskine V, Kuciene R, Medzioniene J, Benetis R. (2014). Association between obesity and high blood pressure among Lithuanian adolescents: a cross-sectional study. Italian Journal Pediatrics. 40 (1): 1-10.

[19] Parker ED, Sinaiko AR, Kharbanda EO, Margolis KL, Daley MF, et al. (2016). Change in weight status and development of hypertension. Pediatrics. 137 (3): 1-9.

[20] Bilal M, Haseeb A, Saeed A, Saeed A, Ghaffar P. (2020). Prevalence and risk factors of hypertension among children attending outpatient department of a tertiary care hospital in Karachi. Cureus. 12 (5): 1-9. 
[21] Gomes RS, Quirino IS, Pereira RM, Vitor BM, et al. (2011). Primary versus secondary hypertension in children followed up at an outpatient tertiary unit. Pediatr nephrol. 26: 441-47.

[22] Lava SA, Bianchetti MG, Simonetti GD. (2014). Salt intake in children and its consequences on blood pressure. Pediatr Nephrol. 17: 1-8.

[23] Leyvraz M, Chatelan A, Costa BR, Taffe P, et al. (2018). Sodium intake and blood pressure in children and adolescents: a systematic review and meta-analysis of experimental and observational studies. International Journal of Epidemiology; 47 (6): 1796-1810.

[24] He FJ, Marrero NM, MacGregor GA. (2008). Salt and blood pressure in children and adolescents. Journal of human hypertension. 22: 4-11.

[25] Kelley GA, Kelley KS, Tran ZV. (2008). The eefect of exercise on resting blood pressure in children and adolescents: A meta-analysis of randomized controlled trial. Prev Cardiol. $6(1): 8-16$. 